\title{
Experimental and Analytical Investigation of Reinforced Concrete Beams with Large Web Opening under Pure Torsion
}

\author{
Ahmed H. Abdel-kareem*, Ahmed M. Abd El Salam
}

Department of Civil Engineering, Benha Faculty of Engineering, Benha University, Egypt

${ }^{*}$ Corresponding author, Associate Prof., E-mail: ahmed.abdelkareem@bhit.bu.edu.eg

\begin{abstract}
This research presents the experimental and analytical results for reinforced concrete (RC) beams with rectangular large web openings under pure torsion. Fifteen specimens were tested; one solid specimen without opening, six specimens without reinforcement around opening as if an opening is created in an existing beam; where the investigated parameters were opening width, opening height and opening eccentricity from the longitudinal beam axis, and eight specimens with reinforcement installed around the opening to reduce the effect of the opening on the torsional behavior; where the investigated parameters were the shapes and amounts of the reinforcement around the opening. The test results showed that installing stirrups and horizontal reinforcement bars in the chords above and below the openings efficiently increased the cracking and ultimate torque of the tested specimens; where using inclined stirrups by $45^{\circ}$ to the longitudinal axis of the specimens increased the ultimate torque to be about $90 \%$ of that of the solid specimen. Installing closed stirrups around the opening had small effect on enhancing the torsional behavior of the tested specimen compared with using horizontal and vertical reinforcement bars. The analytical model based on Modified Variable Angle Truss Model (MVATM) used to obtain the torque-rotation curves for beams under pure torsion was modified to incorporate the beams with large web opening which have different arrangements of reinforcement around the opening. MATLAB program language was used to obtain the analytical torque-rotation curves for the specimens that have reinforcement around the opening which were in good agreement with the experimental results.
\end{abstract}

Keywords- pure torsion, web opening, reinforced concrete beams, Modified Variable Angle Truss Model.

\section{INTRODUCTION}

In most buildings, the need for openings in the structural elements became very necessary to pass pipes, air conditioning, and service ducts. The openings in the beams may take different shapes with different dimensions depending on the service conditions. Creating a web opening will modify the behavior of the beam to be more complex. The design of RC beams under torsional moment in the present different building codes [1-3] are based on the investigations carried out on solid concrete beams. In addition, the codes do not give any recommendations for the design of concrete beams with opening subjected to torsional moment. The openings are classified according to their dimensions into two categories, large openings and small openings. Mansur et al. [4] and Abul Hasnatet al. [5] defined the large openings to have a length greater than the height of the chord above or below the opening, and the small openings otherwise.

There are many previous researches conducted on the effect of the presence of openings on the torsional behavior of RC beams. Mansur et al. [4] studied the effect of the opening dimensions and their locations on the behavior of RC beams under pure torsion. El Badry [6] investigated the behavior of high strength $\mathrm{RC}$ beams with web opening under pure torsion theoretically and experimentally, the variables were the concrete strength, the opening sizes and their locations. El badawy [7] studied the effect of the beam width, the opening dimensions and the existence of vertical stirrups on the behavior of RC beams with opening under pure torsion. Abdo et al. [8] investigated the behavior of beams tested under pure torsion with the variables being, the beam depth, the number of the openings, and the spacing between stirrups. Salama et al. [9] carried out an experimental and theoretical investigation on torsional behavior of T-shaped RC beams with large web openings, the study's parameters were flange width, flange thickness, and opening height. Other researches [10-15] studied the strengthening of concrete beams with opening subjected to pure torsion using Fiber Reinforced Polymers. However, most of these researches focused on the geometric dimensions of the openings and did not focus on the effect 
of installing reinforcement around the opening to reduce its effect on the torsional behavior of the beams.

In the last century, a huge number of researchers agreed that the truss model is the most powerful method for reinforced concrete sections subjected to torsion. Raush [16] extended the $45^{\circ}$ truss model for shear design to torsion design. Hsu and Mo [17] have found that, the Rausch's equations overestimated the actual torsional strength of the beams, and as a result, they developed Variable Angle Truss Model (VATM) equations to correct the difference between the experimental and theoretical results. In VATM at the stages before reaching the ultimate torque, there was a difference between theoretical and analytical torque-rotation curves because of the assumption that the beam is cracked from zero load. Bernardo et al. [18-21] had modified the VATM (MVATM) to be capable of predicting the behavior of the beams under torsion for all loading stages, but this model is not capable of predicting the torsional behavior for beams with web opening under pure torsion.

The main objectives of this study are to evaluate the effect of installing reinforcement around large web opening in beams under pure torsion and modifying the MVATM developed by Bernardo et al. to predict the whole torsional behavior of the beams with web openings. The calculation algorithm that integrates the opening with different reinforcement arrangements around it in the MVATM is computationally performed by means of MATLAB program language. The predicted torque-rotation curves for the tested specimens showed good agreement with the experimental ones.

\section{EXPERIMENTAL PROGRAM}

\subsection{Specimens and test matrix}

Fifteen specimens were casted and tested to investigate torsion behavior of RC beams with large web opening. All tested specimens had rectangular cross-sections with an overall depth of $300 \mathrm{~mm}$ and width of $200 \mathrm{~mm}$, and a total length of $1700 \mathrm{~mm}$. The middle part of the specimens with $1300 \mathrm{~mm}$ length was the test zone, which was subjected to pure torsional moment during testing. Each of the specimens had cantilever end parts, which were loaded with two concentrated loads at their ends to produce the torsional moment in the specimens. These cantilevers were heavily reinforced in order to prevent any type of failure during the test. For all the tested specimens, the longitudinal reinforcement consisted of four deformed bars with $12 \mathrm{~mm}$ diameter at each corner of the cross-section extending over the full length of the specimen. The transverse reinforcement of the specimens was $10 \mathrm{~mm}$ diameter at $200 \mathrm{~mm}$ distance. Fig. 1 shows the dimensions and reinforcement details for tested specimens.

Tested specimens had one without opening to be a reference specimen and the reminder tested specimens were sorted in two groups. The first group (group I) included six specimens without reinforcement around opening as if an opening is created in an existing beam. The test parameters were the ratio of the opening width $\left(b_{o}\right)$ to the height of the specimen $(T)$, the ratio of the opening height $\left(h_{0}\right)$ to $(T)$ and finally the ratio of the opening eccentricity from the longitudinal beam axis (e) to (T), as shown if Fig. 2.The second group (group II), included eight specimens that had the same opening dimensions $(60 \mathrm{~mm}$ height and $600 \mathrm{~mm}$ width) with different shapes and amount of reinforcement around the opening, in order to reduce the effect of the opening on the torsional behavior. The details of the installed reinforcement around the openings are shown in Fig. 3.Table 1 summarizes the details for all tested specimens.
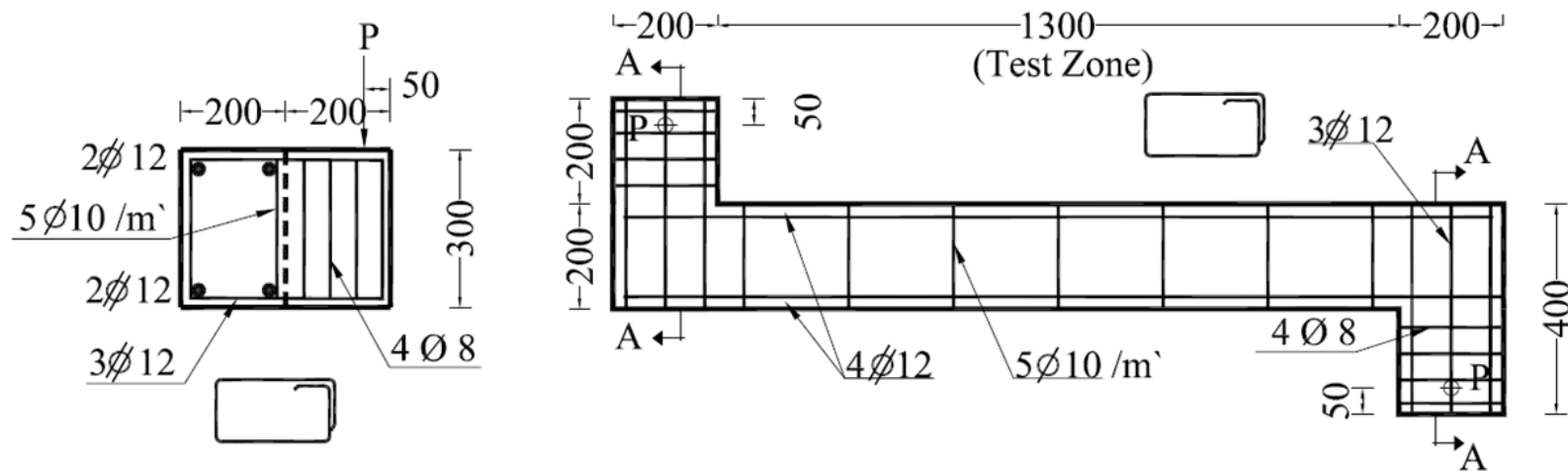

Fig. 1.The dimensions and reinforcement details for tested specimens 


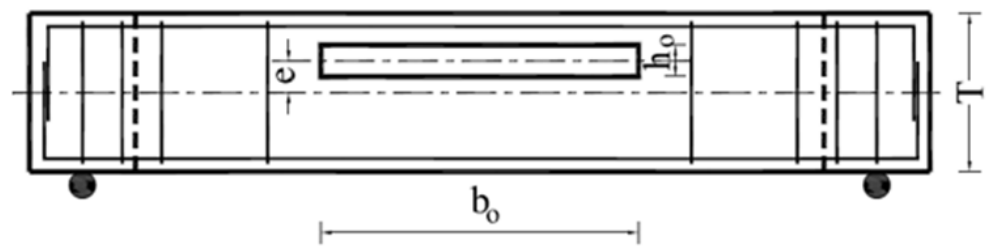

Fig. 2. Notation of the opening for group I

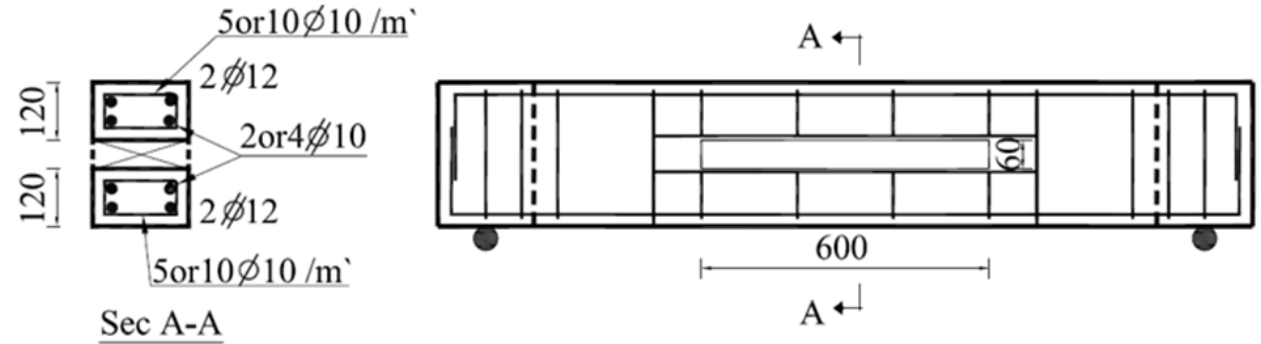

a) Specimens $R-2 H-5 V, R-2 H-10 V, R-4 H-5 V$ and $R-4 H-10 \mathrm{~V}$
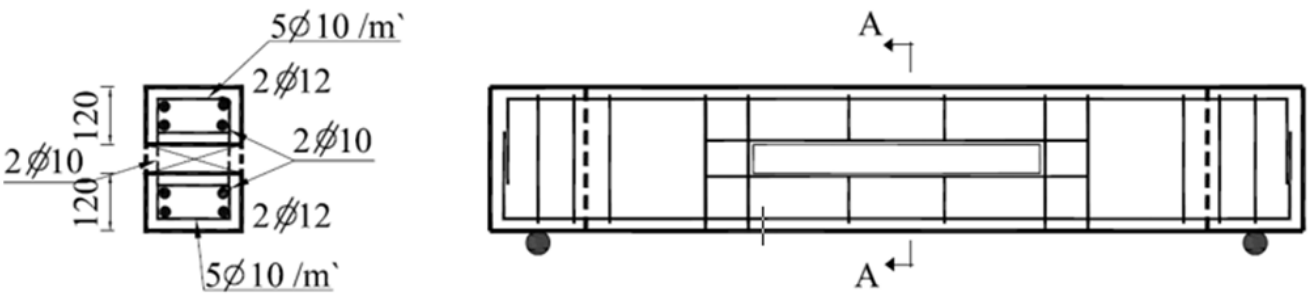

$\underline{\operatorname{Sec} A-A}$
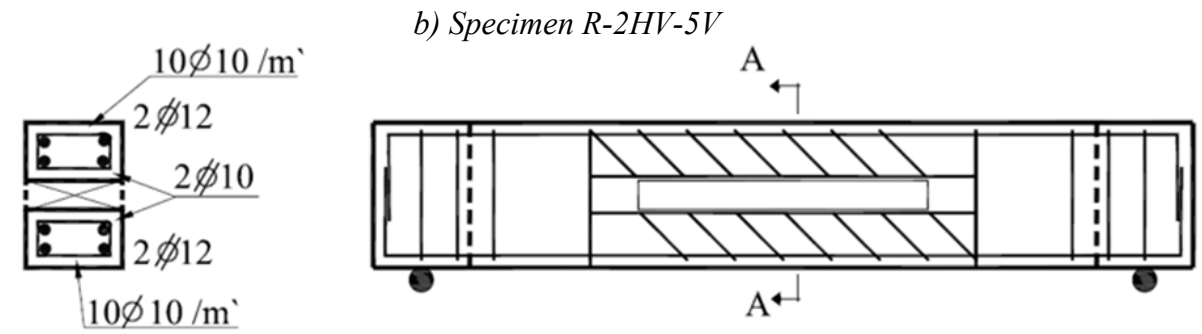

Sec A-A

c) Specimen $R-2 H-10 I$
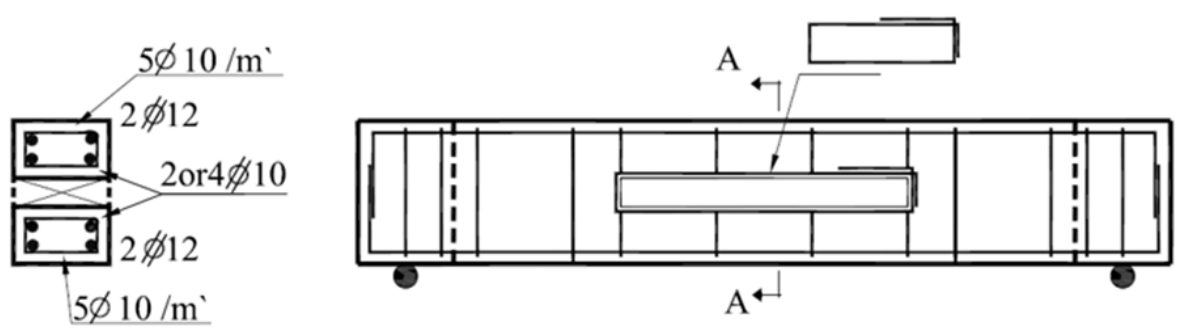

$\underline{\operatorname{Sec} A-A}$

d) Specimens $R-2 S-5 V$ and $R-4 S-5 V$

Fig. 3.Reinforcement details around the opening for group II

The nomenclatures for the two tested groups are shown in Fig. 4.Forgroup (I), the first letter (O) indicates that the specimen without reinforcement around the opening, the second number indicates the ratio $\left(\mathrm{b}_{\mathrm{o}} / \mathrm{T}\right)$, the number after the hyphen points the ratio $\left(\mathrm{h}_{\mathrm{o}} / \mathrm{T}\right)$ and the number after the second hyphen refers to the ratio (e/T).For group II, the 
first letter (R) indicates that the specimen with reinforcement around the opening, the number and the letter after the first hyphen indicate the amount of reinforcement bars around the opening and its locations (H: Horizontal, HV: Horizontal and vertical, and S:

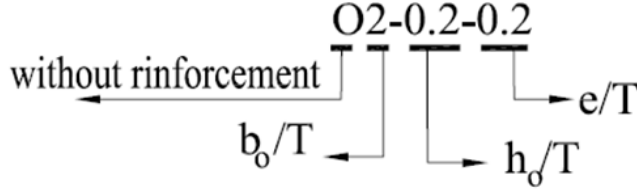

a) Without reinforcement around the opening
Stirrups), the number and the letter after the second hyphen refer to the number of stirrups and their inclination states respect to the longitudinal axis of the specimen in the chords above and below the opening (V: Vertical, and I: Inclined).

Fig. 4. Nomenclatures for the tested specimens

Table 1: Outline of experimental program

\begin{tabular}{|c|c|c|c|c|c|c|c|c|}
\hline \multirow{2}{*}{$\begin{array}{l}\text { Test } \\
\text { group }\end{array}$} & \multirow{2}{*}{$\begin{array}{l}\text { Specimen } \\
\text { code }\end{array}$} & \multicolumn{2}{|c|}{ Opening size } & \multirow{2}{*}{$\begin{array}{c}\text { Opening* } \\
\text { location }\end{array}$} & \multicolumn{2}{|c|}{$\begin{array}{l}\text { Reinforcement bars } \\
\text { around the opening }\end{array}$} & \multicolumn{2}{|c|}{$\begin{array}{c}\text { Stirrups in the chords } \\
\text { above and below the } \\
\text { opening }\end{array}$} \\
\hline & & $\begin{array}{l}\text { Width } \\
\left(\mathrm{b}_{\mathrm{o}}\right) \\
\mathrm{mm}\end{array}$ & $\begin{array}{l}\text { Depth } \\
\left(\mathrm{h}_{\mathrm{o}}\right) \\
\mathrm{mm}\end{array}$ & & $\begin{array}{l}\text { Top and } \\
\text { bottom }\end{array}$ & $\begin{array}{l}\text { Left and } \\
\text { right }\end{array}$ & No. /m` & $\begin{array}{l}\text { Inclination } \\
\text { angle** }\end{array}$ \\
\hline Solid & $\mathrm{S}$ & - & - & - & - & - & - & - \\
\hline \multirow{6}{*}{ 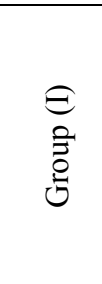 } & O1-0.2 & 300 & \multirow{2}{*}{60} & \multirow{4}{*}{ at center } & - & - & - & - \\
\hline & $\mathrm{O} 2-0.2$ & 600 & & & - & - & - & - \\
\hline & O1-0.4 & 300 & \multirow{2}{*}{120} & & - & - & - & - \\
\hline & $\mathrm{O} 2-0.4$ & \multirow{3}{*}{600} & & & - & - & - & - \\
\hline & O2-0.2-0.1 & & \multirow{2}{*}{60} & $30 \mathrm{~mm}$ & - & - & - & - \\
\hline & $\mathrm{O} 2-0.2-0.2$ & & & $60 \mathrm{~mm}$ & - & - & - & - \\
\hline \multirow{8}{*}{$\begin{array}{l}\widehat{\Xi} \\
\cong \\
0 \\
0\end{array}$} & $\mathrm{R}-2 \mathrm{H}-5 \mathrm{~V}$ & \multirow{8}{*}{600} & \multirow{8}{*}{60} & \multirow{8}{*}{ at center } & \multirow{2}{*}{2} & - & 5 & \multirow{5}{*}{90} \\
\hline & $\mathrm{R}-2 \mathrm{H}-10 \mathrm{~V}$ & & & & & - & 10 & \\
\hline & $\mathrm{R}-4 \mathrm{H}-5 \mathrm{~V}$ & & & & \multirow{2}{*}{4} & - & 5 & \\
\hline & $\mathrm{R}-4 \mathrm{H}-10 \mathrm{~V}$ & & & & & - & 10 & \\
\hline & R-2HV-5V & & & & \multirow{2}{*}{2} & 2 & 5 & \\
\hline & R-2H-10I & & & & & - & 10 & 45 \\
\hline & $\mathrm{R}-2 \mathrm{~S}-5 \mathrm{~V}$ & & & & \multicolumn{2}{|c|}{2 as closed stirrups } & 5 & \multirow{2}{*}{90} \\
\hline & R-4S-5V & & & & \multicolumn{2}{|c|}{4 as closed stirrups } & 5 & \\
\hline
\end{tabular}

*Vertical distance between centerline of the opening and the longitudinal axis of the specimen.

**Respect to the longitudinal axis of the specimen.

\subsection{Material properties}

The specimens that were tested in this investigation were made from local materials. The aggregate was composed from natural sand with 2.7 fineness moduli and $16 \mathrm{~mm}$ maximum aggregate size crushed dolomite. Cement used was Ordinary Portland Cement (OPC-42.5 grade). The target concrete compressive strength $\left(f_{c u}\right)$ was $30 \mathrm{MPa}$. The actual $f_{c u}$ was determined from cubes casted and cured simultaneously with the tested specimens. The steel bars of $8 \mathrm{~mm}$ diameter were mild steel, and steel bars of $10 \mathrm{~mm}$ and $12 \mathrm{~mm}$ diameter were high grade steel. The measured yield strength of $10 \mathrm{~mm}$ and $12 \mathrm{~mm}$ diameter were 435 and $525 \mathrm{MPa}$, respectively.

\subsection{Test setup}

The test set-up is executed to apply pure torsion on the test zone of the specimens which were simply supported on two movable supports, capable of rotation and inclination in the vertical direction. The torsion was applied to the specimens by applying two downwards concentrated loads at the ends of the cantilevers parts by using hydraulic jack 
of $100 \mathrm{kN}$ capacity connected to a proving ring to measure the vertical load. The applied load was distributed equally to the two cantilever parts by rigid spreader steel beam, and transferred to the point load on the cantilevers by a steel rod. Two dial gauges mounted under both loaded points to measure the deflections during the experimental test in order to determine the rotation angle. All specimens were loaded incrementally until failure. The side surfaces of the specimens were painted in a white color to aid the observation of the cracks development during testing. All cracks propagation were monitored. The test setup is shown in Fig. 4.

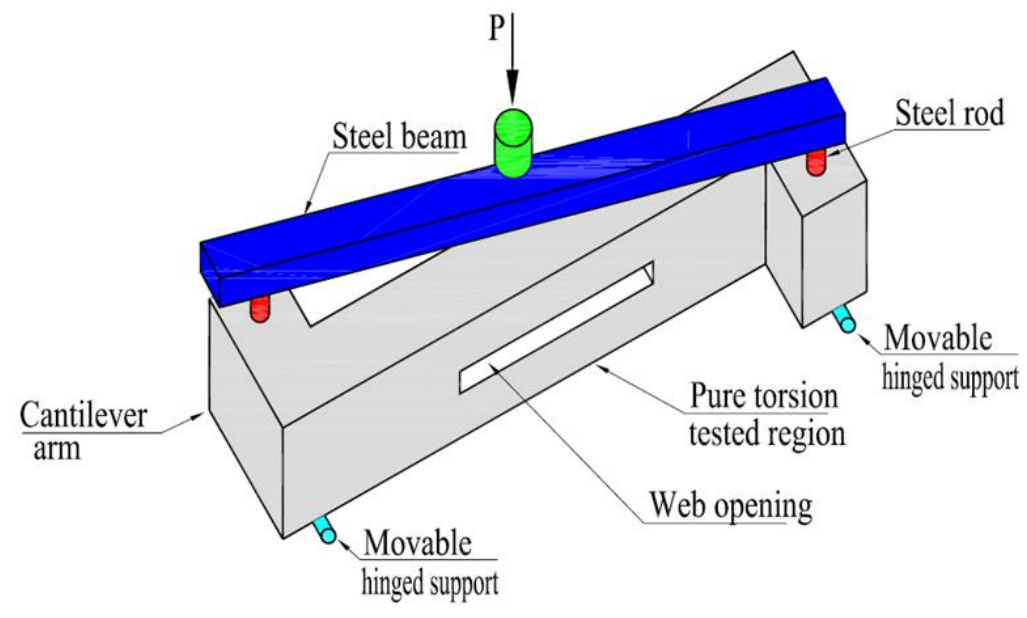

a) Schematic test setup.

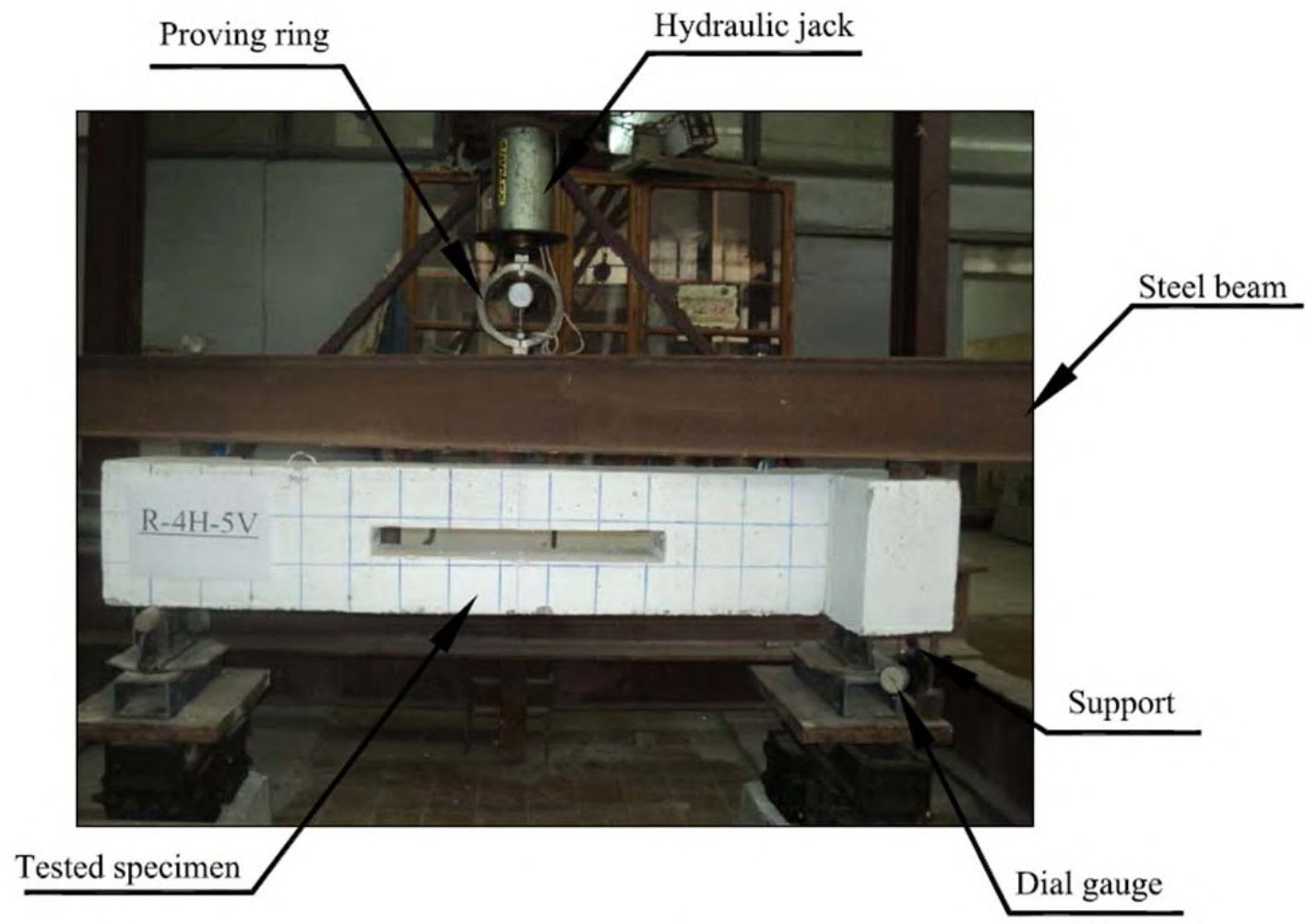

b) Test setup and support details.

Fig. 4. General view of experimental setup. 


\section{TEST RESULTS AND DISCUSSIONS}

\subsection{Torque-Rotation curves}

\subsubsection{Specimens without reinforcement around opening}

The torque-rotation relationship for the specimens of group I were compared with that of the solid specimen, as shown in Fig. 5. It is noted that the torsional curves were divided into two sections. The first section of the curves was linear up to the cracking torsion, and the solid specimen behaved as plain concrete and similar to the specimens without reinforcement around opening. The second section of the curves was nonlinear and the rotation angle increased rapidly with increasing the torsional moment indicating the post-cracking behavior, and was very short for the specimens of the group I which rapidly failed after cracking. In comparing with the solid specimen, the rotation angles decreased from 11-15\% when the opening length increased from $300 \mathrm{~mm}$ to 600 $\mathrm{mm}$, while the rotation angle decreased from $2-5 \%$ when the opening depth increased from $60 \mathrm{~mm}$ to $120 \mathrm{~mm}$. The torsional behavior of the specimen with eccentric opening by 0.1 the beam height, $T$, was the best compared to the specimen with concentric opening and the specimen with eccentric opening by $0.2 \mathrm{~T}$.

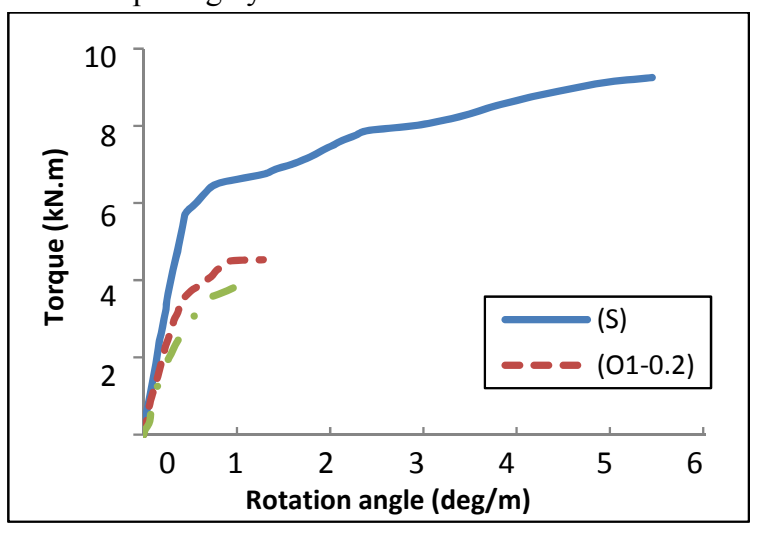

a) Specimens with variable opening length

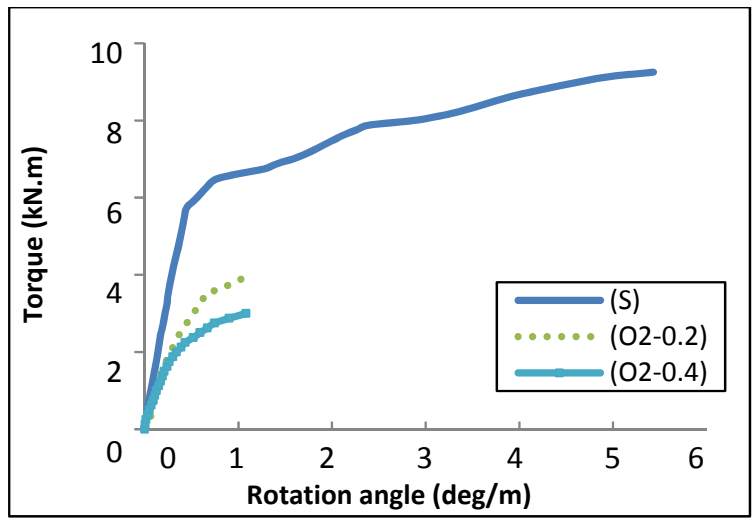

b) Specimens with variable opening depth

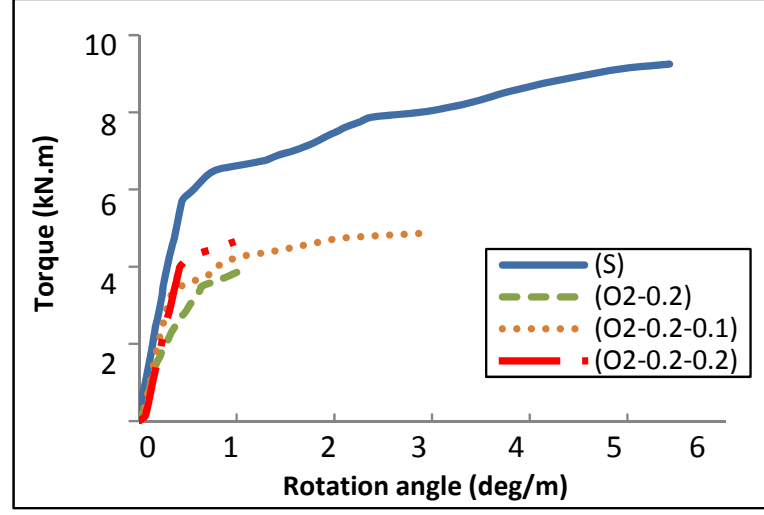

c) Specimen with variable opening location

Fig. 5. Torque-Rotation curves for the specimens without reinforcement around opening

\subsubsection{Specimens with reinforcement around opening}

The first and the second sections of the torque-rotation curves for the specimens of group II behaved similar to that of group I, except that the rotation angles and the torsional moments increased due to the effect of installing reinforcement around the openings, as shown in Fig. 6. The rotation angles increased $12-52 \%$ when the vertical stirrups in the chords above and below the opening increased from $5 \varnothing 10 / \mathrm{m}$ to $10 \varnothing 10 / \mathrm{m}$. While, the rotation angles increased $10-44 \%$ when the longitudinal reinforcement bars above and below the opening increased from $2 \varnothing 10$ to $4 \varnothing 10$. The rotation angles are almost equal for the different shapes of reinforcement around the opening, which were either stirrups or horizontal and vertical reinforcement bars. The rotation angle increased about $10 \%$ when the stirrups inclined by $45^{\circ}$ to the longitudinal axis of the specimen comparing with that with vertical stirrups. From Fig. 6, specimen $\mathrm{R}-2 \mathrm{H}-10 \mathrm{I}$ is the nearest one to the solid specimen, because using inclined stirrups in the perpendicular direction to the fracture lines that were inclined by $45^{\circ}$.

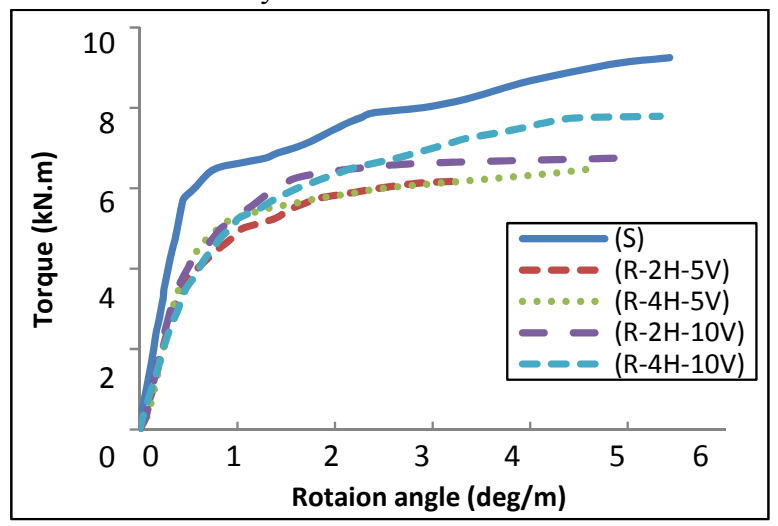

a) Variable longitudinal reinforcement bars and stirrups in the chords above and below opening 


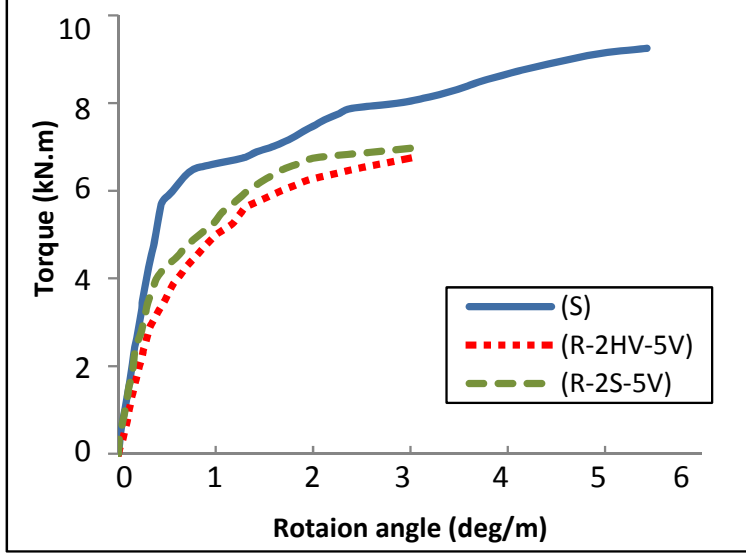

b) Variable shape of reinforcement around the opening

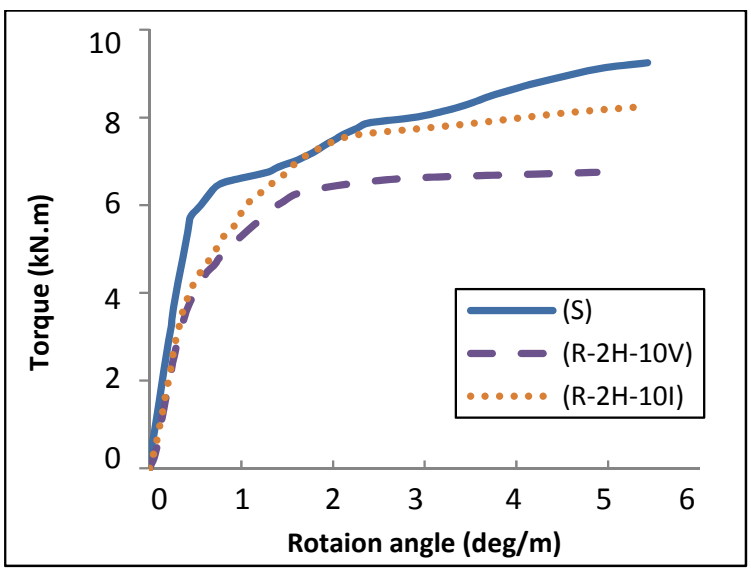

c) Variable stirrups inclination in the chords above and below the opening

Fig. 6 Torque-Rotation curves for the specimens with reinforcement around opening

\subsection{Cracking and ultimate torsional moment}

For all tested specimens, table 1 summarizes the torque and rotation angles at cracking and ultimate stage.

3.2.1 Specimens without reinforcement around opening The cracking load, $T_{c \text { r, }}$ and the ultimate load, $T_{u}$, decreased with increasing the opening length or depth. As the opening length increased from $300 \mathrm{~mm}$ to $600 \mathrm{~mm}, T_{c r}$ and $T_{u}$ decreased by $16-30 \%$ and $11-22 \%$, respectively, while for specimens with opening height that increased from 60 $\mathrm{mm}$ to $120 \mathrm{~mm}, T_{c r}$ and $T_{u}$ decreased by $20-40 \%$ and $14-$ $25 \%$, respectively. Increasing the opening eccentricity to be $0.1 \mathrm{~T}$, increased $T_{c r}$ and $T_{u}$ more than increasing the opening eccentricity to be $0.2 T$. Whilst, comparing to the specimen with concentric opening, $T_{c r}$ and $T_{u}$ increased by $30 \%$ and $27 \%$, respectively, for specimen $02-0.2-0.1$ with opening eccentricity $0.1 \mathrm{~T}$, while $T_{c r}$ and $T_{u}$ increased by $25 \%$ and $16 \%$, respectively, for specimen O2-0.2-0.2 with opening eccentricity $0.2 \mathrm{~T}$.

\subsubsection{Specimens with reinforcement around opening}

The reinforcement around the opening had a great improvement on the cracking and ultimate torque for tested specimens. Increasing the horizontal reinforcement above and below the opening from $2 \varnothing 10$ to $4 \varnothing 10$ increased $T_{c r}$ and $T_{u}$ by $4-10 \%$ and $5-15 \%$ respectively. The increase of the numbers of stirrups and inclining them to the longitudinal axis of the specimen by $45^{\circ}$ in the chords above and below the opening had a great effect on $T_{c r}$ and $T_{u}$. Where increasing the vertical stirrups from $5 \varnothing 10 / \mathrm{m}$ to $10 \varnothing 10 / \mathrm{m}$ increased $T_{c r}$ and $T_{u}$ by $11-18 \%$ and $9-20 \%$ respectively, while for the specimen with inclined stirrups $T_{c r}$ and $T_{u}$ increased by $13 \%$ and $22 \%$ compared with the specimen with vertical stirrups. $T_{c r}$ and $T_{u}$ for the specimens R-2S-5V and R-4S-5V that having closed stirrups around the opening slightly increased more than that for the specimen $\mathrm{R}-2 \mathrm{HV}-5 \mathrm{~V}$ having vertical and horizontal reinforcement bars around the opening. Comparing the previous specimens, which having different arrangements of reinforcement around the opening, with the specimen $\mathrm{R}-2 \mathrm{H}-5 \mathrm{~V}$ that having only horizontal reinforcement bars above and below the opening $T_{c r}$ and $T_{u}$ increased by $9-13 \%$ and $14-18 \%$, respectively.

\subsection{Cracking behavior and failure modes}

From the observation during the experimental work and from the cracks configuration, all the tested specimens had failed in torsion. For the solid specimen, the cracks were diagonal by inclined angle $45^{\circ}$ with the longitudinal axis of the specimen. With increasing the load, diagonal cracks were spread out to perform spiral trajectories on the four sides of the specimens as shown in Fig. 7.a.

For the specimens without reinforcement around opening, the first crack appeared at a corner of the opening and the cracks were concentrated at the chords above and below the opening and no cracks propagated in the solid parts of the beam. The numbers of cracks formed in the two chords were small. The failure occurred either at the top chord above the opening or the bottom chord below the opening. Also cracks performed spiral trajectories on the four sides of the chords, as shown in Fig. 7.b.

For the specimens with reinforcement around opening, the number of cracks in the chords above and below the opening was greater than that in the specimens without reinforcement, and the cracks appeared in the solid parts of the specimens. The number of cracks increased with increasing the amount of reinforcement around the opening, especially increasing the stirrups in the chords above and below the opening. The failure occurred in one of the chords above or below the opening, as shown in Fig. 7.c. 
Table 2: Experimental results

\begin{tabular}{lccccc}
\hline \multirow{2}{*}{$\begin{array}{l}\text { Specimen } \\
\text { code }\end{array}$} & \multicolumn{2}{c}{$f_{c u}$} & \multicolumn{3}{c}{ Ultimate } \\
\cline { 2 - 6 } S & $\mathrm{MPa}$ & $T_{c r}(\mathrm{kN} . \mathrm{m})$ & $\theta_{c r}(\mathrm{deg} / \mathrm{m})$ & $T_{u}(\mathrm{kN} . \mathrm{m})$ & $\theta_{u}(\mathrm{deg} / \mathrm{m})$ \\
\hline O1-0.2 & 32.2 & 6.00 & 0.50 & 4.25 & 5.14 \\
O2-0.2 & 31.8 & 3.00 & 0.29 & 4.00 & 1.20 \\
O1-0.4 & 31.5 & 2.50 & 0.34 & 3.87 & 1.09 \\
O2-0.4 & 31.2 & 2.38 & 0.23 & 3.00 & 1.14 \\
O2-0.2-0.1 & 32.2 & 1.50 & 0.17 & 4.88 & 1.06 \\
O2-0.2-0.2 & 30.5 & 3.25 & 0.29 & 4.63 & 2.80 \\
\hline R-2H-5V & 30.4 & 3.12 & 0.34 & 6.18 & 0.92 \\
R-2H-10V & 30.3 & 3.38 & 0.40 & 6.75 & 3.09 \\
R-4H-5V & 30.0 & 3.75 & 0.40 & 6.50 & 4.63 \\
R-4H-10V & 30.0 & 3.5 & 0.40 & 7.79 & 4.46 \\
R-2HV-5V & 31.5 & 4.13 & 0.63 & 6.75 & 5.08 \\
R-2H-10I & 31.8 & 3.88 & 0.57 & 8.25 & 2.86 \\
R-2S-5V & 33.3 & 4.25 & 0.46 & 7.00 & 5.13 \\
R-4S-5V & 31.8 & 4.00 & 0.34 & 7.05 & 2.97 \\
\hline
\end{tabular}
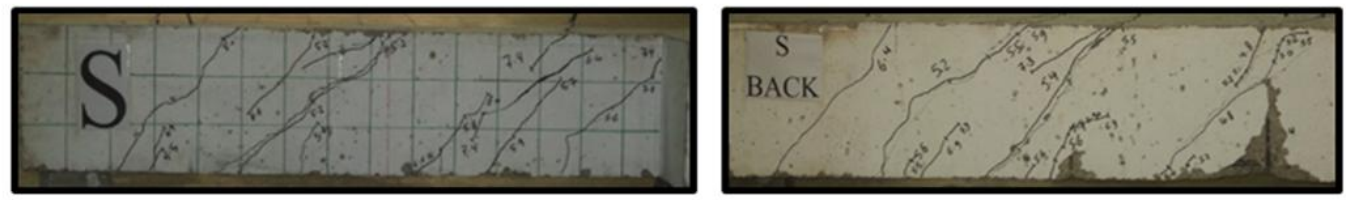

a) Crack pattern for the solid specimen
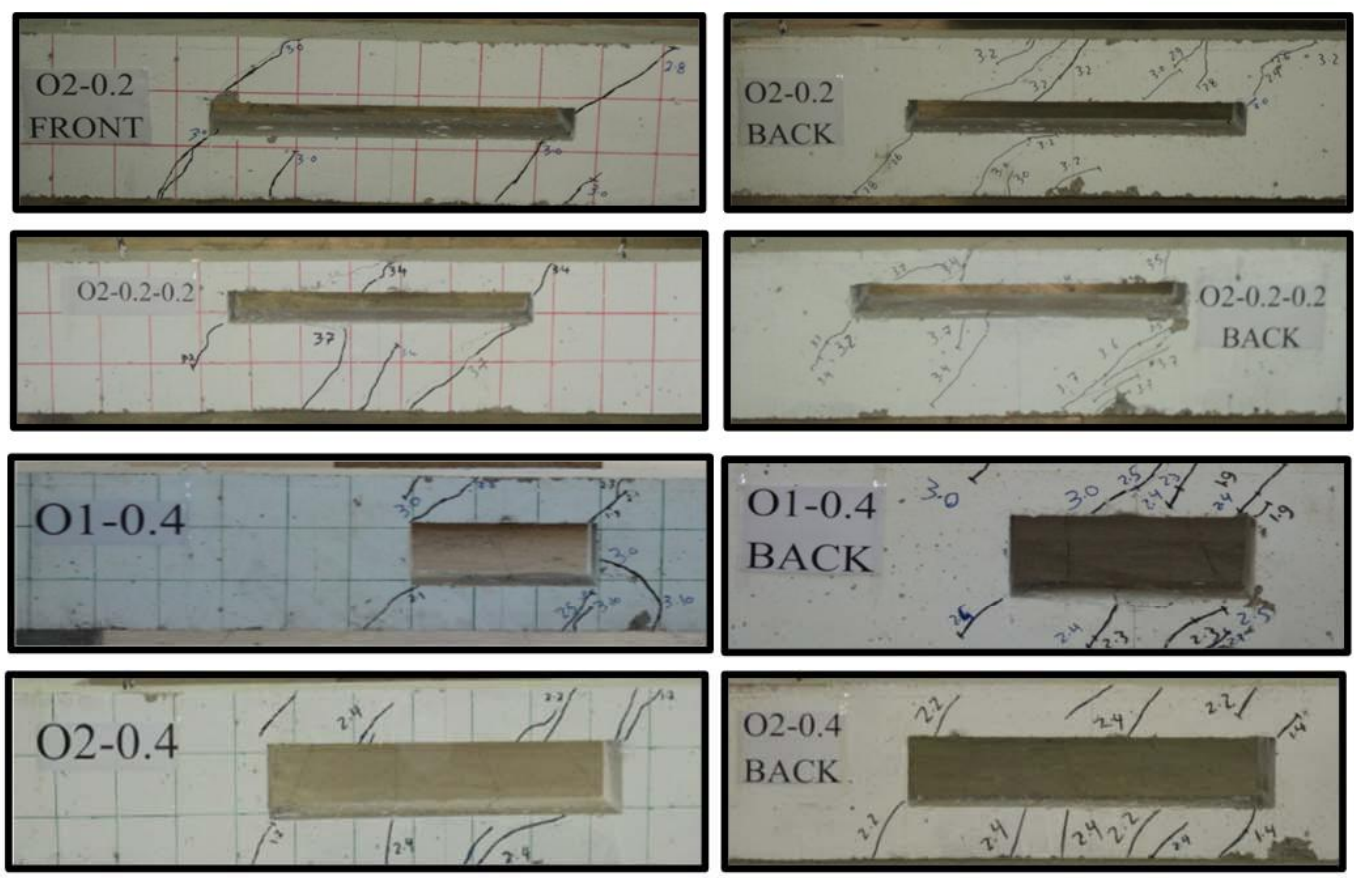

b) Crack pattern for the specimens without reinforcement around the opening 

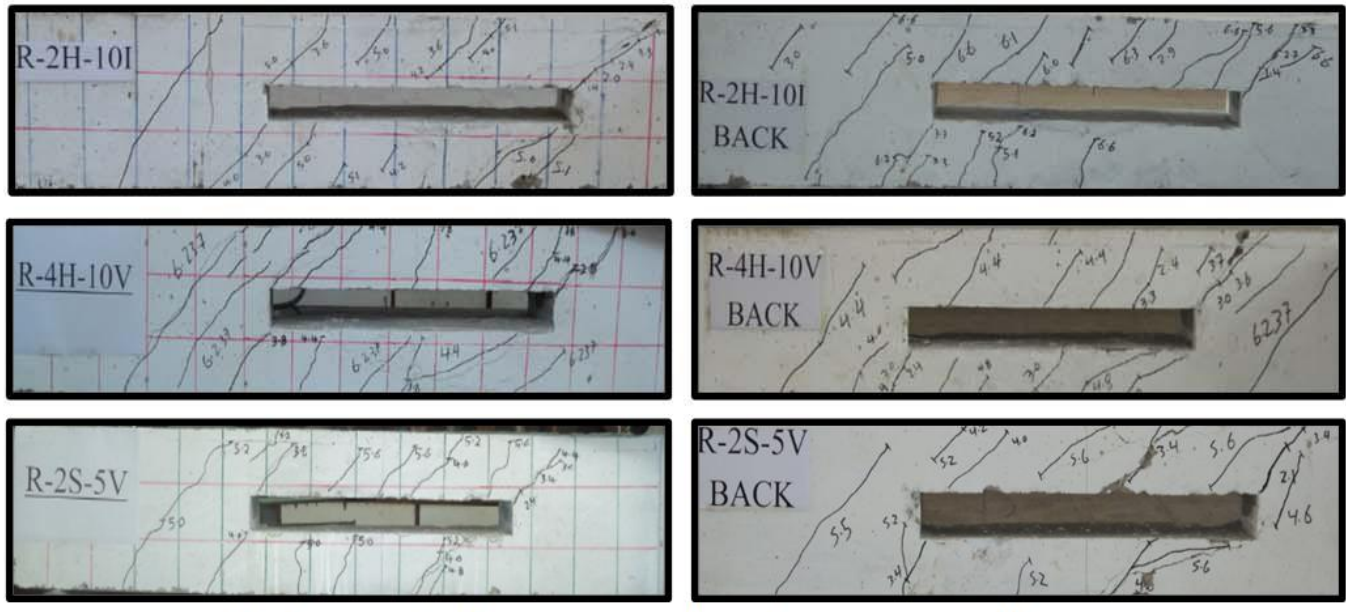

c) Crack pattern for the specimens with reinforcement around the opening

Fig. 7. Cracking patterns for some of tested specimens

IV. ANALYTICAL MODEL

There were two main different theories to predict the ultimate strength of reinforced concrete members subjected to torsion, Skew Bending theory and Space Truss Model theory, the first theory is the basis of the old building codes, and the second theory was the basis of the new building codes.

Rausch has divided the Space Truss Model theory into Truss Analogy and Variable Angle Truss Model (VATM). In VATM when the beam is subjected to torsional moment, it is assumed that the cross section is quintessential to a thin walled tube, the longitudinal bars will become the top and bottom chords of the truss, the stirrups will act as vertical members of the truss, and the perimeter of the outer sides of the concrete beam will act as a series of diagonal strut members, while the concrete core will be neglected as shown in Fig. 8.

Hsu and Mo have found that the Rausch's equation overestimated the actual torsional strength of member; thus, they developed VATM equations according to stress equilibrium, strain compatibility and constitutive laws of materials to correct the difference between the experimental and theoretical results. Hsu and Mo had derived three equilibrium equations to calculate the torque, $T$, the inclined concrete strut angle, $\alpha$, and effective wall thickness, $t_{e}$, as follows:

$$
\begin{aligned}
& T=2 A_{o} t_{e} \sigma_{c d} \sin \alpha \cos \alpha \\
& \cos ^{2} \alpha=\frac{A_{L} f_{l}}{P_{o} \sigma_{c d} t_{e}} \\
& t_{e}=\frac{A_{L} f_{l}}{P_{o} \sigma_{c d}}+\frac{A_{t} f_{t}}{S \sigma_{c d}}
\end{aligned}
$$

Where $A_{L}$ is the total area of the longitudinal reinforcement, $f_{l}$ is the steel stress in the longitudinal reinforcement, $A_{t}$ is the area of one leg of the closed stirrups, $f_{t}$ is the stress in the closed stirrups, $S$ is the

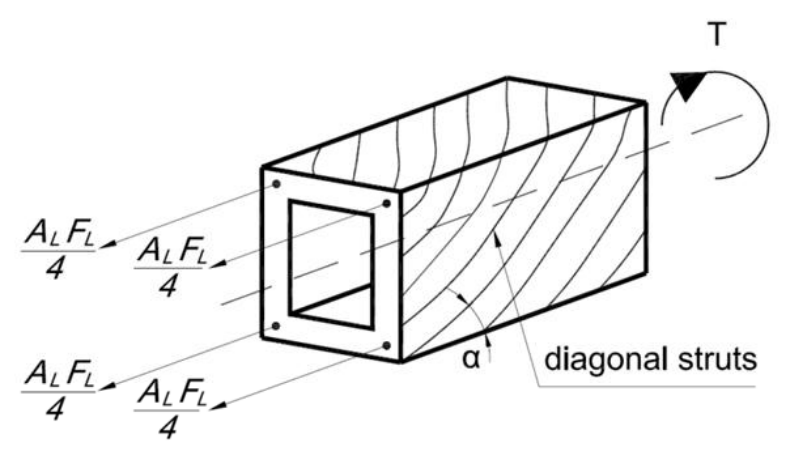

a) General View

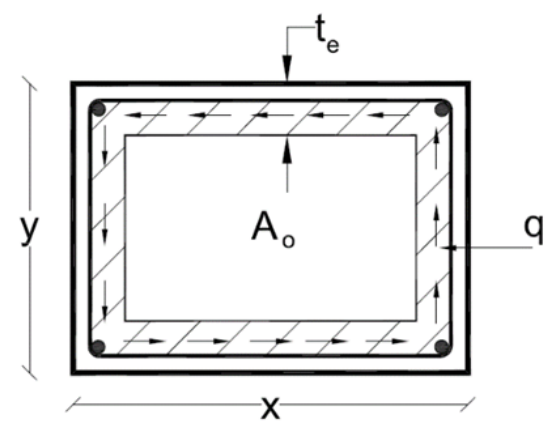

b) Cross Section

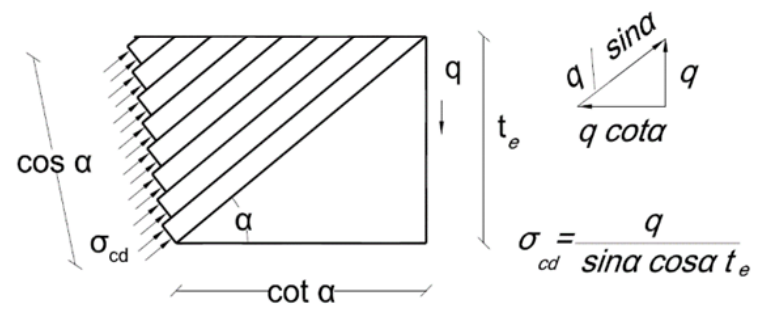

c) Wall Element

Fig. 8. Equilibrium of box section subjected to torsion 
spacing between the closed stirrups, $A_{o}$ is the area limited by center of the flow of the shear stresses as shown in Fig. 8 -a, $A_{o}=\left(x-t_{e}\right)\left(y-t_{e}\right), P_{o}$ is the perimeter of area $A_{o}$, where $P_{o}=2\left(\left(x-t_{e}\right)+\left(y-t_{e}\right)\right)$, and $\sigma_{c d}$ is the stress in the diagonal concrete strut.

To solve a concrete member subjected to torsion by VATM it needs another three compatibility equations to compute the strain of stirrups, $\varepsilon_{t}$, the strain in the longitudinal reinforcement, $\varepsilon_{l}$, and the angle of twist, $\theta$, which is estimated as follows:

$\varepsilon_{t}=\left(\frac{A_{o}^{2} \sigma_{c d}}{p_{o} T \tan \alpha}-\frac{1}{2}\right) \varepsilon_{d s}$

$\varepsilon_{l}=\left(\frac{A_{o}^{2} \sigma_{c d}}{p_{o} T \cot \alpha}-\frac{1}{2}\right) \varepsilon_{d s}$

$\boldsymbol{\theta}=\frac{\varepsilon_{d s}}{2 t_{e} \sin \alpha \cos \alpha}$

Where $\varepsilon_{d s}$ is the maximum compressive strain in the external surface of the concrete strut and taken as 0.0035 .

The stress-strain $(\sigma-\varepsilon)$ relationship for compression concrete diagonal struts must be adopted taking into consideration the softening effect for concrete, as shown in Fig. (9). Belarbi and Hsu [22] proposed $(\sigma-\varepsilon)$ relationship with softening factor for maximum stress in concrete, $\beta_{\sigma}$, and Zhang and Hsu [23] proposed the softening strain corresponding to maximum stress, $\beta_{\varepsilon}$. The stress-strain ( $\sigma-$ $\varepsilon)$ relationship with the softening factors is as follows:

$$
\begin{array}{ll}
\sigma_{c d}=\beta_{\sigma} f_{c}^{\prime}\left[2\left(\frac{\varepsilon_{d s}}{\beta_{\varepsilon} \varepsilon_{o}}\right)-\left(\frac{\varepsilon_{d s}}{\beta_{\varepsilon} \varepsilon_{o}}\right)^{2}\right] & \text { if } \varepsilon_{d s} \leq \beta_{\varepsilon} \varepsilon_{o} \\
\sigma_{c d}=\beta_{\sigma} f_{c}^{\prime}\left[1-\left(\frac{\varepsilon_{d}-\beta_{\varepsilon} \varepsilon_{o}}{2 \varepsilon_{o}-\beta_{\varepsilon} \varepsilon_{o}}\right)^{2}\right] & \text { if } \varepsilon_{d s}>\beta_{\varepsilon} \varepsilon_{o}
\end{array}
$$

Where:

$\beta=\beta_{\varepsilon}=\beta_{\sigma}=\frac{R\left(f_{c}^{\prime}\right)}{\sqrt{1+\frac{400 \varepsilon_{e l}}{\eta}}}$

$\boldsymbol{\eta}=\frac{\rho_{l} \boldsymbol{f}_{\text {syl }}}{\rho_{t} \boldsymbol{f}_{\text {syt }}} \quad$ Where $\begin{cases}\boldsymbol{\eta} \leq 1 \Rightarrow & \boldsymbol{\eta}=\boldsymbol{\eta} \\ \boldsymbol{\eta}>1 \Rightarrow & \boldsymbol{\eta}=\frac{1}{\eta}\end{cases}$

$R\left(f_{c}^{\prime}\right)=\frac{5.8}{\sqrt{\left(f_{c}^{\prime}\right)(M P a)}} \leq 0.9$

$\varepsilon_{e l}=0.7\left(f_{c}^{\prime}\right)^{0.31}(M P a)<2.8$
Where $f_{c}$ is the cylindrical concrete compressive strength $=$ $0.80 f_{c u}, \varepsilon_{e l}$ is the tensile strain in the perpendicular direction of the strut, $\rho_{l}$ and $\rho_{t}$ are the longitudinal and transversal reinforcement ratio, respectively, $f_{s y l}$, and $f_{s y t}$ are yielding stress for longitudinal and transversal respectively, reinforcement.

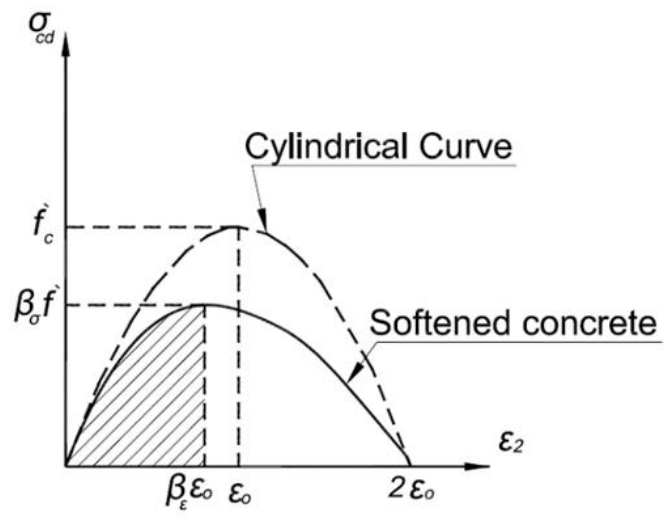

Fig. 9. Stress-strain relationship for the compressed concrete strut

The stress of concrete diagonal struts, $\sigma_{c d}$, is obtained as follows:

$\sigma_{c d}=\boldsymbol{k}_{\mathbf{1}} \boldsymbol{\beta} \boldsymbol{f}_{c}^{\prime}$

Where $K_{l}$ is the ratio of the average stress to the maximum stress for the stress diagram of the concrete struts and obtained by integration of Eqs. (7) and (8).

The VATM is very successful in predicting the ultimate torsional moment for a concrete beam, but cannot predict the whole torsional behavior of the beam. However in VATM the concrete core is neglected, but in the stages before the ultimate load the concrete beams is not fully cracked, that leads to a difference between theoretical and experimental $T-\theta$ curves. Bernardo et al. had adjusted VATM which became Modified Variable Angle Truss Model (MVATM) to be able to predict the behavior of reinforced concrete beam under torsion in all loading stages. Bernardo et al. divided the $T-\theta$ curves into three zones according to the experimental results as shown in Fig. 10. Where zone 1 is non-cracking state, zone 2.a is cracked state, and finally zones $2 . b$ and 3 are cracked state and ultimate state. 


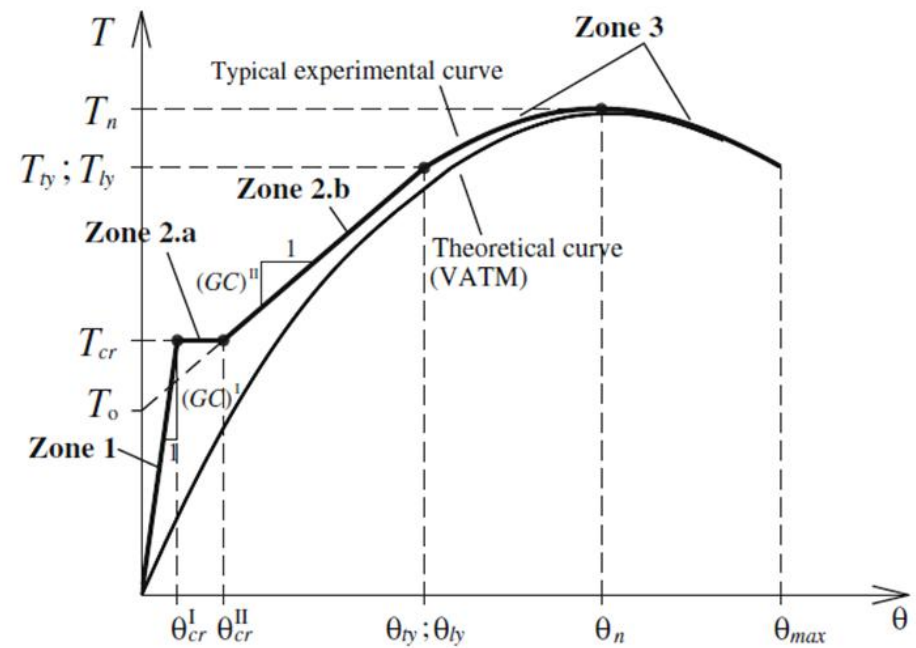

Fig. 10 Theoretical T- $\theta$ curves for a RC beam under pure torsion, Bernardo et al. [18]

In zone 1 , the cracking torsional moment, $T_{c r}$, is set to be the limit for this zone. To correct the VATM results, the contribution of the concrete core in resisting torsion must be involved by adding the torsional stiffness of the concrete core, $K_{c}$, to the each calculated points of $T-\theta$ curve as follows:

- Calculate the equivalent torsional stiffness

$$
K_{e q}=\frac{T}{\theta}
$$

- Calculate the torsional stiffness of the concrete core

$$
K_{c}=0.292 E_{c} C
$$

- Calculate the total torsional stiffness

$$
\boldsymbol{K}_{t}=\boldsymbol{K}_{e q}+\boldsymbol{K}_{c}
$$

- Calculate the corrected twisting angle

$$
\boldsymbol{\theta}_{\text {cor }}=\frac{T}{K_{t}}
$$

Where $C$ is torsional factor $=\boldsymbol{\Omega} \boldsymbol{x}^{\mathbf{3}} \boldsymbol{y}, x$ and $y$ are the smallest and largest dimensions of the section, $\Omega$ is St. Venant's coefficient [24], $E_{c}$ Young's modulus of the concrete calculated according to ECP-203 [3].

Hsu and Mo proposed the following equation to compute $T_{c r}$.

$T_{c r}=2 A_{c} t\left(0.2076 \sqrt{f_{c}^{\prime}(M P a)}\right)$
Hsu [25] proposed an empirical equation to estimate the effective cracking torque, $T_{\text {cref, }}$, which considering the effect of both longitudinal and transversal reinforcement in the cracking torque as follows:

$T_{\text {cref }}=\left[1+4\left(\rho_{l}+\rho_{t}\right)\right] T_{c r}$

Where $t$ is the wall thickness $=\frac{\mathbf{1 . 2 A _ { c }}}{\boldsymbol{p}_{\boldsymbol{c}}}, A_{c}$ and $P_{c}$ are the area and the perimeter limited by the outer perimeter of the section.

In zone 2.a, the torque is constant while the rotation angle increases with relatively small value. This stage is neglected in this research.

In zone 2.b and 3, the calculated torsional moments from $T-\theta$ curve are in good agreement with the experimental results, but the twisting angles must be corrected to take into account that the concrete core is not fully effective in the model as before. Where the torsional stiffness of the concrete core decrease from $T_{\text {cref }}$ to the ultimate torsional moment, $T_{n}$. As a result, the rotation angles in this stage increase linearly from $T_{\text {cref }}$ to $T_{n}$ by $\Delta \theta$ which is equal to zero at $T_{n}$ and with full value at $T_{\text {cref }}$, as shown in Fig. 11, and $\Delta \theta$ is calculated as follows:

$\Delta \theta_{\text {cor }}=\theta_{\boldsymbol{n}}-\boldsymbol{\theta}_{\boldsymbol{n}, \mathrm{cor}}$

Where $\theta_{n}$ is the rotation angle corresponding to $T_{n}$ calculated from VATM and $\theta_{n, c o r}$ is the rotation angle corresponding to $T_{n}$ calculated from MVATM. 


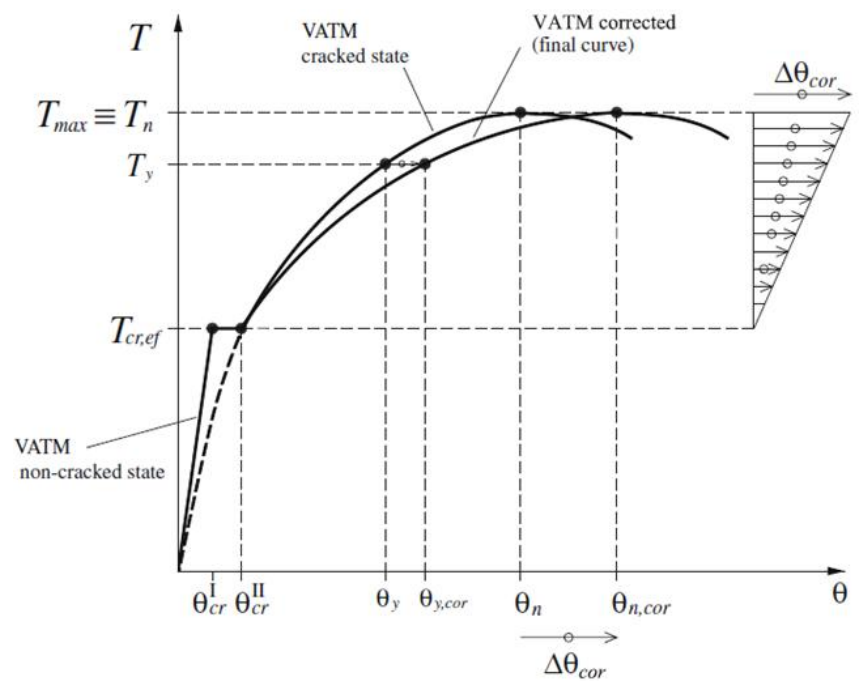

Fig. 11. Correction of T- $\theta$ curve for zone 2-b and 3, Bernardo et al. [18].

To apply MVTAM on the RC beams with web opening, the chords above and below the opening simulated as shown in Fig. 12-a, and the following assumptions were imposed:

- The failure occurs in one of the chords above or below the opening.

- The ultimate torsion capacity of the beam is the summation of the ultimate torsion of the two chords above and below the opening.

- The two chords above and below the opening rotate by the same angle.

The contribution of stirrups in resisting torque in the MVATM was derived for vertical stirrups. For inclined stirrups by angle $\alpha$ with the horizontal direction, the force in stirrups was analyzed to two components, one in a vertical direction $\left(A_{t} F_{t} \sin \alpha\right)$ and the another in the horizontal direction $\left(A_{t} F_{t} \cos \alpha\right)$ which was added to the force in the longitudinal bars $\left(A_{L} F_{L}\right)$ as shown in Fig. 12b.

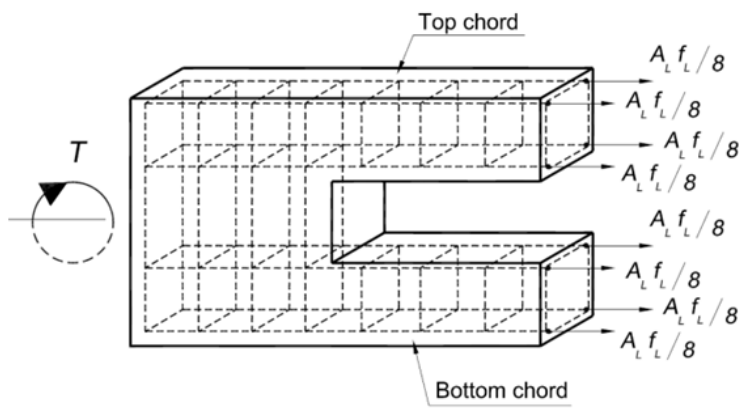

a) Vertical stirrups

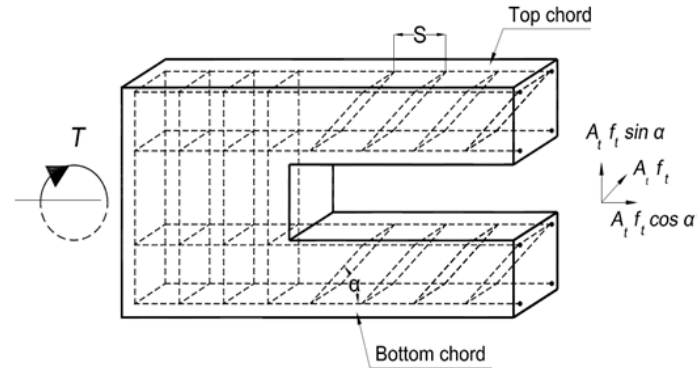

b) Inclined stirrups

Fig. 12. Simulation of a RC beam with web opening in MVATM

Calculation algorithm to obtain the torsional behavior for beams with different arrangements of reinforcements around web openings is shown in Fig. 13. The procedure can be epitomized in the following steps:

1- Select value of the compressive strain at the surface of concrete strut $\varepsilon_{d s} \leq 0.0035$.

2- Assume $\alpha=45^{\circ}$, and $t_{e=} A_{o h} / p_{h}$ as initial value. Where $A_{o h}$ is the area bounded by the centerline of the outermost closed stirrups, and $P_{h}$ is the perimeter of the stirrups, then calculate $\beta$ from Eq. (9).

3- Calculate $K_{l}, \sigma_{c d}, T, \varepsilon_{t}, \varepsilon_{l}$, and $t_{e}$, from Eqs. (13), (7), (8), (1), (4), (5), and (3) respectively.

4- Compare $t_{e}$ 'with the assumed $t_{e}$. If the difference is close continue to step 5, else take the calculated $t_{e}$ in step 2.

5- Calculate $\alpha$ from Eq. (2), then compare $\alpha$ with the assumed $\alpha$.If the difference is close continue to step 6 , else take the calculated $\alpha$ in step 2 . 
6- Calculate $\beta$ from Eq. (9), then compare $\beta$ with the assumed $\beta$.If the difference are close continue to step 7, else take the calculated $\beta$ in step 2 .

7- Calculate $\theta$, and $T_{\text {cref }}$ from Eqs. (6), and (19).If $T \leq$ $T_{\text {cref, }}$ calculate $K_{t}$, and $\theta_{\text {cor }}$ from Eqs. (16) and (17), else go to step 8.

8- Calculate the correct values of $\theta$ from $T_{\text {cref }}$ to $T_{u}$ according to Eq. (20).

9- Repeat the previous steps with another value for $\varepsilon_{d s}$.
A computing procedure was carried out with program language MATLAB. Full theoretical $T-\theta$ curves were obtained for the solid specimen and the specimens with reinforcement around the opening. The comparison between the predicted and experimental $T-\theta$ curves of the tested specimens are shown in Fig. 14, which shows that the proposed model has a good agreement with the experimental results.

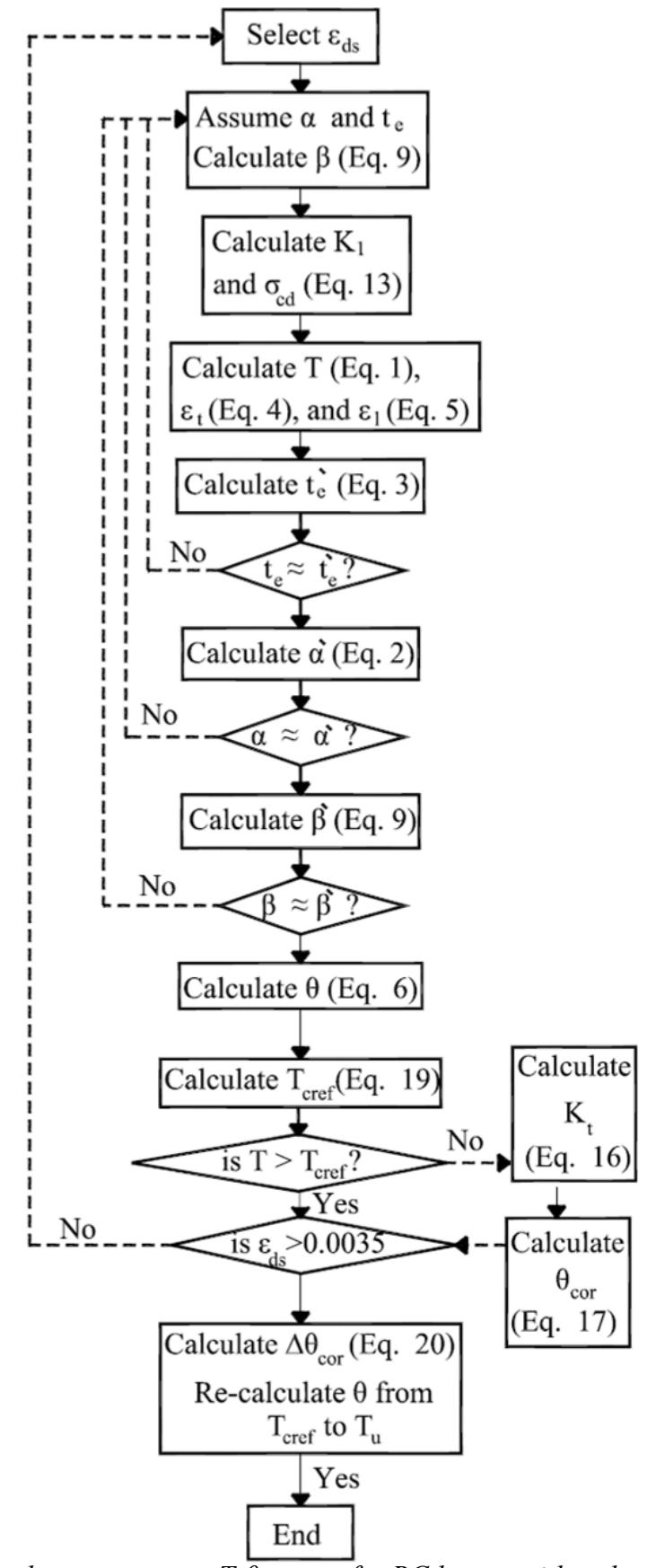

Fig. 13. Flowchart to compute T- $\theta$ curves for RC beams with web opening. 


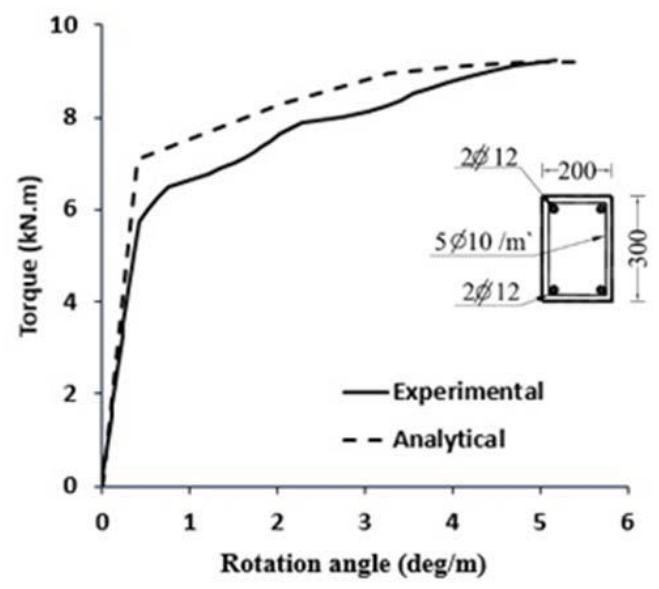

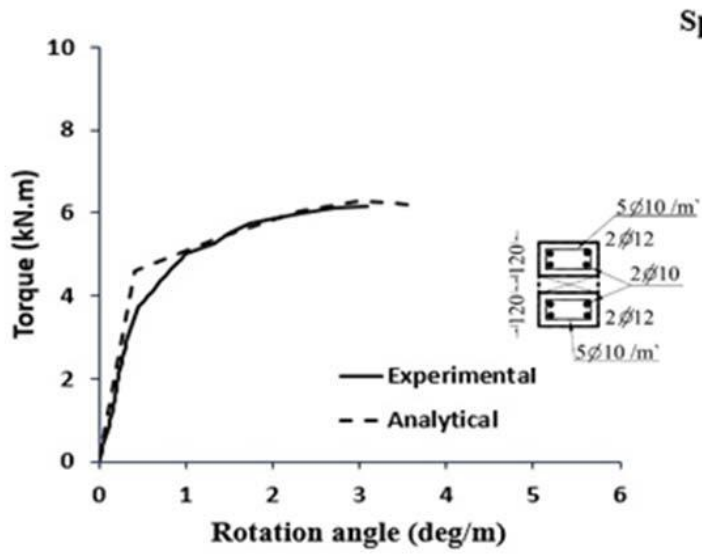

Specimen ( R-2H-5V)

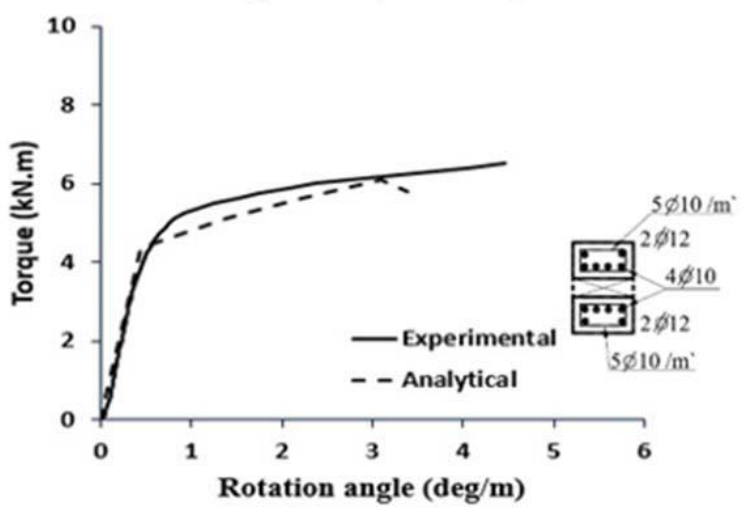

Specimen ( R-4H-5V )

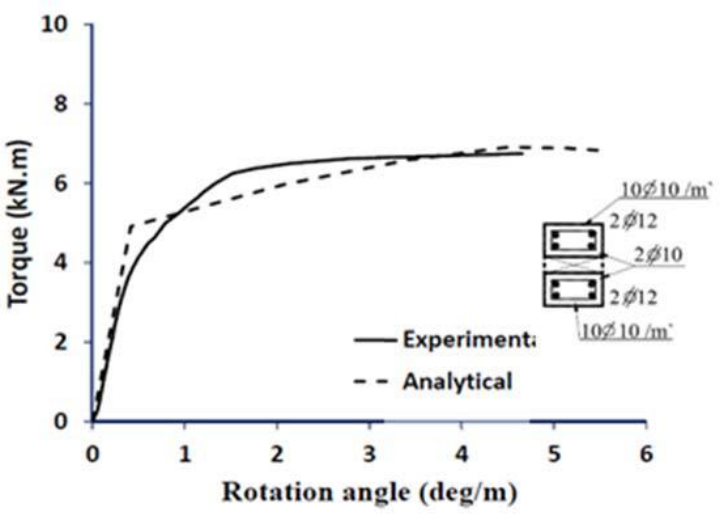

Specimen ( R-2H-10V)

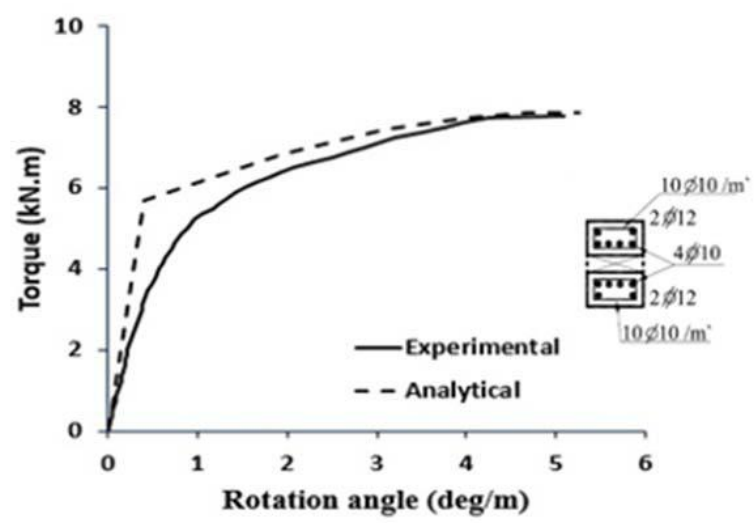

Specimen ( R-4H-10V) 


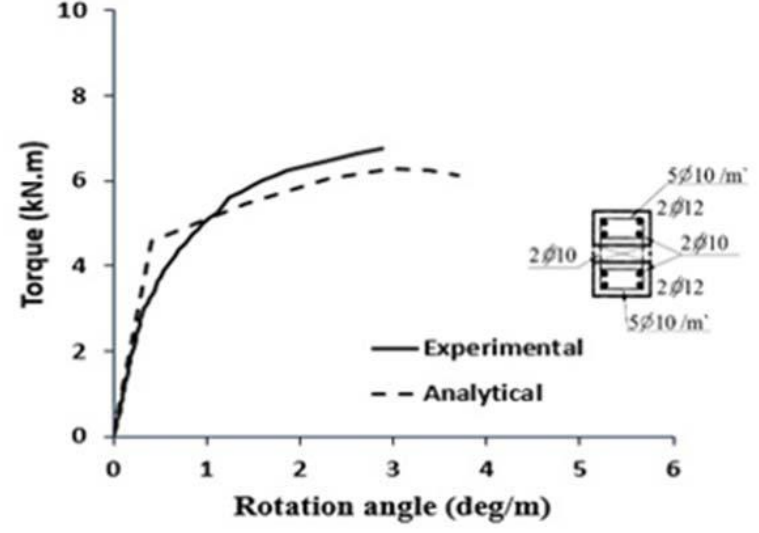

Specimen ( R-2HV-5V)

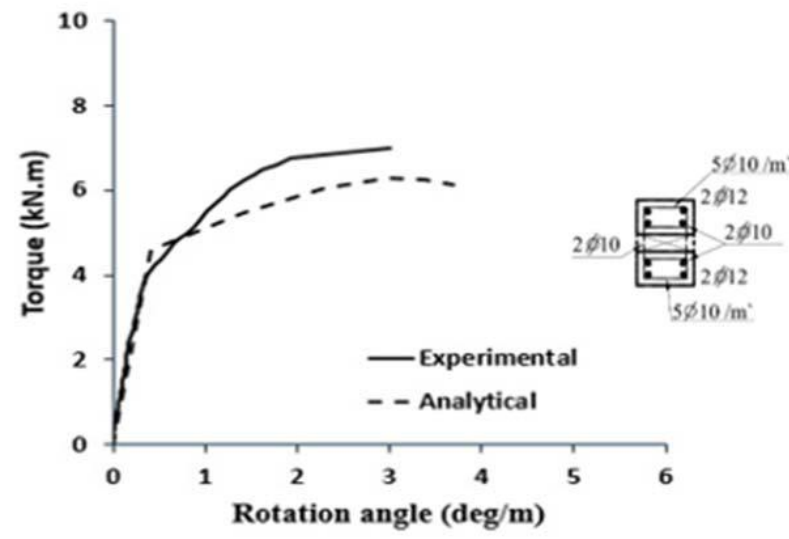

Specimen ( R-2S-5V)

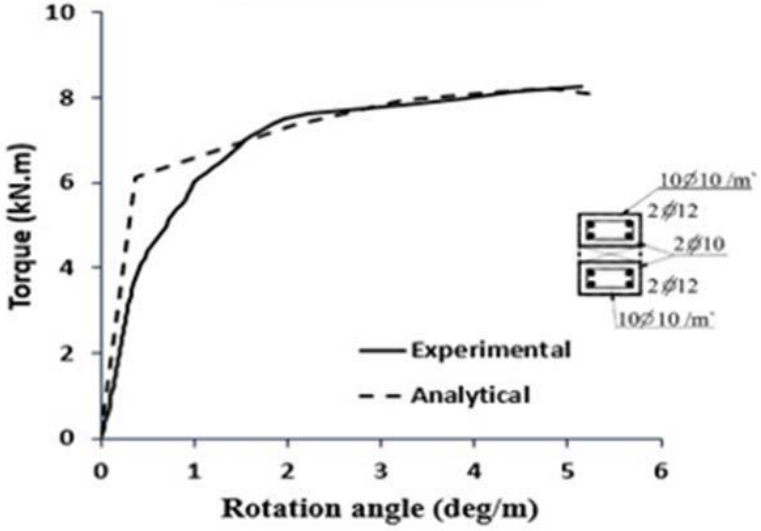

Specimen ( R-2H-10I )

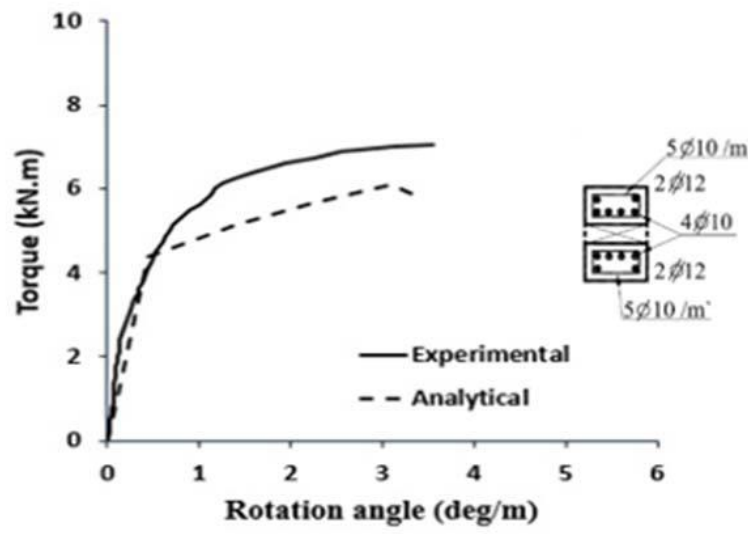

Specimen ( R-4S-5V)

Fig. 14. Comparison between the analytical and experimental T- $\theta$ curves.

\section{CONCLUSION}

In this paper, the torsional behavior of $\mathrm{RC}$ beams with large web opening with and without reinforcement around the opening is investigated. An analytical model was presented to obtain the torque-rotation curves for beams with reinforcement around the opening. The validity of the model was verified through comparing the analytical torque-rotation curves with the test results. Based on the fifteen specimens that were tested under pure torsion the main conclusions are summarized as following:

- Diagonal cracks were spread out to perform a spiral trajectory inclined by $45^{\circ}$ with the longitudinal axis of the tested specimens on the four sides with increasing the applied torque. For specimens without reinforcement around the opening, the cracks started at a corner of the opening and performed only in the chords above and below the opening, and the number of cracks was small. For specimens with reinforcement around the opening the number of cracks increased compared to the ones without reinforcement around the opening, and the cracks were presented in the solid parts of the specimens, in additional to the crakes in the chords above and below the opening.

- The geometrical parameters of the web opening effected on the behavior of the specimens without reinforcement around the opening. Doubling the opening depth was more effective in decreasing the cracking and ultimate torque than doubling the opening length. The torsional behavior was enhanced when the opening become eccentric in respect to the longitudinal axis of the beam, where for opening eccentricity 0.1 and 0.2 of the beam height, the cracking and ultimate load increased by $25-30 \%$ and $16-22 \%$ respectively.

- Installing reinforcement around opening notably enhanced the torsional behavior of the beams. Where, the ultimate torque for the specimen with inclined stirrups by $45^{\circ}$ to the longitudinal axis of the specimens at the chords above and below the opening was $90 \%$ of that for the solid specimen. 
- Increasing the number of stirrups from $5 \varnothing 10 / \mathrm{m}$ to $10 \varnothing 10 / \mathrm{m}$ in the chords above and below the opening increased the cracking and ultimate load by $11-18 \%$ and $9-20 \%$ respectively.

- The cracking and ultimate torque increased $4-10 \%$ and $5-15 \%$, respectively, with increasing the horizontal reinforcement above and below the opening from $2 \varnothing 10$ to $4 \varnothing 10$.

- Replacing closed stirrups around the opening by vertical and horizontal reinforcement bars had a minor effect on the torsional behavior.

- The proposed modifications on the Modified Variable Angle Truss Model (MVATM) is reliable for predicting the torque-rotation curve for beams with large web opening subjected to pure torsion. There was a good agreement between the predicted and experimental torque-rotation curves for tested specimens with reinforcement around the opening.

\section{REFERENCES}

[1] ACI Committee 318, Building Code Requirements for Structural Concrete and Commentary (ACI 318-08). Farmington Hills, Mich, American Concrete Institute, 2008.

[2] European Committee for standardization. CEN, EN 19921-1 Eurocode 2: Design of concrete structures - Part 1-1: general rules and rules for buildings, Brussels, Belgium; 2004.

[3] Egyptian Code Committee, ECP-203. Egyptian Code for Design and Construction of concrete Structures, HBRC, Giza, Egypt; 2018.

[4] Mansur M, Ting S, Lee S. Torsion tests of RC beams with large openings. ASCE Journal. 109. 1983; 1780-1791.

[5] Abul Hasnat A, Faisal F, Wafa AA. Pre-stressed concrete beams with a small opening under torsion. ASCE Journal. 114. 1988; 1626-43

[6] El Badry K, Essa MS, Abdel-Kareem. Behavior of high strength concrete beams with web opening subjected to torsion. Ph.D. thesis, department of structural Engineering, Cairo Univ., Egypt, 2003.

[7] El-Badawy M. Torsional behavior of RC beams with web opening. MSc. Thesis. Faculty of Engineering, Ain-shames University, Cairo, Egypt, 2010.

[8] Abdo T, Mabrouk R. Effect of web openings on the structural behavior of RC beams subjected to pure torsion. MATEC Web of Conferences. 2017.

[9] Salama A E, Kassem M E, and Mahmoud A A. Torsional behavior of T- shaped reinforced concrete beams with large web openings. J Build Eng. 18, 2008, 84-94.

[10] Atea R.S. Torsional behavior of reinforced concrete Tbeams strengthened with CFRP strips. Case Studies in Constr Mater, 7. 2017; 110-27.
[11] Soluit A, Motawea M, EL-Sayed K, and Shalaby S. Torsional behavior of RC beams strengthened with Fiber Reinforced Polymer sheets. Engineering Research Journal, Helwan University, 114, 2007; 102-19.

[12] Tan E, and Uy B. Experimental study on straight composite beams subjected to combined flexure and torsion. J Constr Steel Research, 65, 2009; 784-93.

[13] Pawlakn W, Kamin' ski M. Cracking of reinforced concrete beam sunder torsion-theory and experimental research. Archives of civil and mechanical engineering, 12, 2012; 368-75.

[14] Deifalla A, Ghobarah A. Behavior and analysis of inverted T-shaped RC beam sunder shear and torsion. J Struct Eng. 68, 2014; 57-70.

[15] Deifalla A, Ghobarah A. Simplified analysis of RC beams torsionaly strengthened using FRP. BBFS, 2005; 381-86.

[16] Rausch E. Design of reinforced concrete in torsion (Berechnung des Eisenbetonsgegen Verdrehung). $\mathrm{PhD}$ thesis, Technische Hochschule, Berlin, 1952.

[17] Hsu T, and Mo Y. Softening of concrete in torsional members - Theory and Tests. ACI Journal Proceedings, 82, 1985; 290-03.

[18] Bernardo A, and Lopes M R. Modified Variable Angle Truss-Model for torsion in reinforced concrete beams. Mater and Struct, 45, 2012; 1877-1902

[19] Bernardo A, and Lopes M R, Andrade A. Softened truss model for reinforced NSC and HSC beams under torsion: A comparative study. Eng Struct, 42, 2012; 278-96.

[20] Bernardo A, and Lopes M R. Plastic analysis and twist capacity of high-strength concrete hollow beams under pure torsion. Eng Struct, 49, 2013; 190-201.

[21] Bernardo A, Teixeira M. Modified softened truss-model for prestressed concrete beams under torsion. J Buil Eng, 19, 2018; 49-61.

[22] Belarbi A, and Hsu T. Constitutive laws of concrete intension and reinforcing bars stiffened by concrete. Struct J, 91, 1994; 465-74.

[23] Zhang X, Hsu T. Behaviour and analysis of $100 \mathrm{MPa}$ concrete membrane elements. J Struct Eng, 124, 1998; 24 34.

[24] Saint-Venant B. Me'moiresur la torsion des prismes (Memory on prisms under torsion).Me'moires des savantse'trangers, Imprimerie Impe'riale, 14, 1856, Paris, $233-560$.

[25] Hsu T. Torsion of structural concrete behavior of reinforced concrete rectangular members. ACI, 18, 1968; 261-306.

[26] Abd El Salam M A; Khalil G I, and Abdel-Kareem A H. Web opening effect on torsional resistance of reinforced concrete beams. Msc Thesis, Dept. of Civil Engineering, Benha University, 2013. 